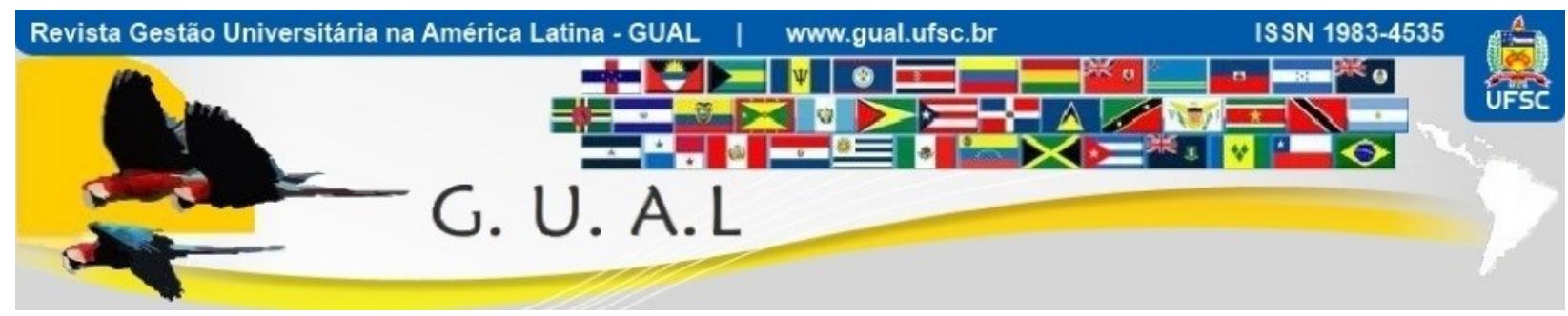

DOI: http://dx.doi.org/10.5007/1983-4535.2016v9n2p260

\title{
INTERNACIONALIZAÇÃO DE CURSOS STRICTO SENSU: UMA INVESTIGAÇÃO SOBRE A DISTÂNCIA PSÍQUICA E AS PRÁTICAS ADOTADAS
}

\section{INTERNATIONALIZATION OF GRADUATION PROGRAMS: AN INQUIRY OF THE EFFECTS OF PSYCHIC DISTANCE AND PRACTICES}

\author{
Gustavo da Rosa Borges, Doutorando \\ Universidade Regional de Blumenau - FURB \\ gustavodarosaborges@,gmail.com \\ Mohamed Amal, Doutor \\ Universidade Regional de Blumenau - FURB \\ mohamedamal.amal@gmail.com
}

Recebido em 01/abril/2014

Aprovado em 27/janeiro/2016

Sistema de Avaliação: Double Blind Review

Esta obra está sob uma Licença Creative Commons Atribuição-Uso. 


\title{
RESUMO
}

A internacionalização como estratégia de inserção em mercados externos não é um fenômeno restrito aos negócios. Nota-se, também, que as Instituições de Ensino Superior (IES) estão cada vez se inserindo no mercado global para o desenvolvimento de estratégias específicas para dar suporte às suas políticas de ensino, pesquisa e extensão. A internacionalização deste tipo de organizações não é recente, no entanto, cada vez mais as IES vêm adotando esta estratégia, especialmente no caso de cursos de pós-graduação stricto sensu. Objetivando verificar se a distância psíquica interfere na escolha dos parceiros de universidades estrangeiras, realizou-se uma pesquisa exploratória e qualitativa com sete cursos stricto sensu de uma universidade localizada no sul do Brasil. Os resultados revelam que a distância psíquica não determina a escolha dos países envolvidos, e sim, a rede de relação dos professores. A rede de relações na literatura de Negócios Internacionais foi considerada como um fator importante para minimizar os efeitos negativos da distância psíquica, proporcionando condições para adquirir conhecimento e competências. Mostrou-se ainda, que os cursos stricto sensu se inserem no mercado internacional de educação superior com um relativo baixo grau de conhecimento. Contudo, numa trajetória gradativa, as IES vão adquirindo o conhecimento e as competências necessárias para a cooperação com programas de pós-graduação de universidades estrangeiras utilizando-se de suas redes estabelecidas por professores e pesquisadores.

Palavras-chaves: Internacionalização. Instituições de ensino superior. Pós-Graduação Stricto Sensu. Distância psíquica.

\begin{abstract}
The internationalization as strategy of insertion in foreign markets is not a phenomenon restricted to businesses. It is noticed also, that the higher education institutions (HEIs) are increasingly being inserted in the global market to the development of specific strategies for improving the quality and construction of specific competences that support their educational policies, research and extension. The internationalization of such organizations is not new, however, increasingly HEIs are adopting this strategy, especially for postgraduate studies courses. Aiming to verify whether the psychic distance interfere in the choice of partners of foreign universities was held an exploratory and qualitative research with seven courses at a university located in southern Brazil. The results show that the psychic distance does not determine the choice of countries, and yes, the network relationship of teachers. The network of relationships in the International Business literature was considered as an important factor to minimize negative effects of the psychic distance, providing specific conditions to acquire knowledge and skills. It has been shown also that the masters and doctoral courses are inserted in the international market of higher education with a relatively low degree of knowledge. However, in a gradual way, HEIs are acquiring the knowledge and skills necessary for cooperation with foreign universities postgraduate programs, using the network of professors and researchers.
\end{abstract}

Keywords: Internationalization. High education institution. Graduation programs. Psychic distance. 


\section{INTERNACIONALIZAÇÃO DE CURSOS STRICTO SENSU: UMA INVESTIGAÇÃO SOBRE A \\ DISTÂNCIA PSÍQUICA E AS PRÁTICAS ADOTADAS \\ DOI: http://dx.doi.org/10.5007/1983-4535.2016v9n2p260}

\section{INTRODUÇÃO}

Com o advento da internacionalização o mundo está se tornando cada vez mais interligado (JACKSON, 2008), sendo que a globalização acelera o processo de internacionalização (HSU; PEREIRA, 2008). Novos empreendimentos internacionais já existem há séculos, sendo que as instituições buscam obter vantagens sobre o processo de internacionalização (MCDOUGALL; OVIATT, 1994).

Há em especial, um intenso ritmo de internacionalização em empresas que trabalham com intenso conhecimento (BRENNNAN; GARVEY, 2009); e este é o caso de Instituições de Ensino Superior (IES).

A internacionalização interfere também nos negócios de IES, onde muitas já incluem em seus programas metodologias que melhor preparam os seus alunos para atuarem globalmente (JACKSON, 2008). Cabe ressaltar que o ensino superior está passando por uma série de transformações distintas que variam em forma e intensidade em todo o mundo, incluindo práticas de globalização e internacionalização (MARGINSON, 2007).

Por meio da cooperação, cada vez mais IES estão pretendendo e praticando a internacionalização, no entanto em alguns países, este fenômeno começou a surgir no início do século (HUANG, 2007). A internacionalização tende a acarretar resultados positivos para as IES (ALTBACH; KNIGHT, 2007; MARGINSON, 2007; MURPHY, 2007; BOGOTCH; MASLIN-OSTROWSKI; BOSTROM，2010; BÉGIN-CAOUETTE，2012; OLATOKUN; UTULU, 2012) e para o seu país de origem (MURPHY, 2007; BYUN e KIM, 2011), especialmente por gerar aprendizagem (MELIN, 1992; JOHANSON; VAHLNE, 2009).

A internacionalização da aprendizagem vem ocorrendo há muito tempo (KERR, 1990); no entanto, o processo de internacionalização de IES tem sido crescente nos últimos anos (ALTBACH; KNIGHT, 2007; FATHI VAJARGAH; KHOSHNOODIFAR, 2013), sendo que o campo de estudos desta área vem recentemente, despertando o interesse de pesquisadores (JOHANSON; VAHLNE, 2009; CORYELL et al., 2012).

No entanto, não existem muitos trabalhos que evidenciem o entendimento da internacionalização de IES por meio das teorias de negócios internacionais, especialmente no Brasil, e com foco em cursos stricto sensu. Cabe ressaltar que estes tipos de cursos recebem no Brasil apoio governamental para se internacionalizar, inclusive, sua internacionalização é avaliada como positiva pelos órgãos que os certificam. Portanto, podemos dizer que o processo de internacionalização tende a fazer parte faz parte de um curso stricto sensu. 
Mais especificamente, não se tem observado estudos que enfatizem a escolha estratégica do local ao qual a o curso stricto sensu busca se internacionalizar. Johanson e Vahlne (1977, 2009), Sapienza, Autio e Zahra (2003) e Andersson (2004) manifestam que esta escolha ocorre por meio da distância psíquica, observando que as instituições tendem a iniciar o seu processo de internacionalização em países psiquicamente mais próximos.

Buscando preencher esta lacuna, o presente artigo tem por objetivo responder a seguinte questão: 0 efeito da distância psíquica interfere no processo de internacionalização de cursos stricto sensu de IES?

A resposta para esta questão tem como base os estudos de Johanson e Vahlne (1977) ao estudarem o modelo de Uppsala, sendo precursores da distância psíquica. Johanson e Vahlne (2009) destacam que a escolha inicia por países mais pertos, visto haver um maior desconhecimento sobre o mercado de países mais afastados. Neste caso, o objetivo principal deste artigo é verificar se a distância psíquica é levada em consideração no processo de internacionalização de cursos stricto sensu de IES no Brasil.

O presente artigo irá contribuir para uma lacuna pouco explorada sobre a distância psíquica e a aquisição de conhecimento por parte de cursos stricto sensu. Assim sendo, as investigações aqui levantadas contribuirão para uma verificação se a distância psíquica ainda é empregada como um fator de escolha para o começo do processo de internacionalização. De igual forma, verificar-se-á se os cursos investigados adotam um conhecimento sobre o mercado internacional de modo paulatino, e como o fazem.

\section{FUNDAMENTAÇÃO TEÓRICA}

A fundamentação teórica será dividida em duas partes: o processo de internacionalização e a internacionalização de IES.

\subsection{O PROCESSO DE INTERNACIONALIZAÇÃO}

Processos de internacionalização são caracterizados por um alto grau de complexidade, variabilidade e heterogeneidade, onde a organização deve incorporar estratégias dinâmicas ao longo do tempo com base nas experiências adquiridas para gerar conhecimento (MELIN, 1992).

Buscando um melhor conhecimento sobre o mercado, foi idealizado o modelo de Uppsala. Nele, conhecimento e incerteza são dois conceitos interligados (FIGUEIRA-DE- 
LEMOS; JOHANSON; VAHLNE, 2011). Ao iniciar seu processo de internacionalização, empresas devem escolher países psicologicamente mais pertos, levando em conta a distância psíquica (ANDERSSON, 2004), conforme preconizado no modelo de Uppsala de Johanson e Vahlne (1977).

A premissa básica do modelo de Uppsala é a falta de conhecimento sobre o mercado estrangeiro, e isto acaba sendo um obstáculo para as operações internacionais, no entanto, com o tempo, elas vão adquirindo conhecimento, o que fortalece a sua necessidade de internacionalização. No entanto, um maior compromisso tende a ocorrer com o tempo, igualmente a aquisição de aprendizagem (JOHANSON; VAHLNE, 1977; 2009).

A aprendizagem através do desenvolvimento de conhecimento experimental sobre os mercados estrangeiros é necessária, a fim de superar a "distância psíquica" desses mercados, ou seja, superar as diferenças entre países (MELIN, 1992). Buckley (2002) enfatiza que as empresas começam a se internacionalizar inicialmente de uma maneira não planejada. No entanto, é importante haver uma definição estratégica neste processo (MELIN, 1992).

Uma das vantagens da internacionalização é a troca de informações, onde a empresa que se internacionaliza aprende com as experiências adquiridas em outro país (HSU; PEREIRA, 2008). Forsgren (2002) enfatiza que as empresas, por vezes, investem em mercados estrangeiros sem possuírem conhecimento experimental. Isto acaba ocorrendo porque els buscam conhecimento incremental, e, por conseguinte, ocorre a acumulação de conhecimento gradual. Johanson e Vahlne (2009) propõem uma aquisição de conhecimento gradual, oriunda das relações. Os autores criaram um mecanismo básico de internacionalização em 1977 e aprimoraram em 2009 (figura 1).

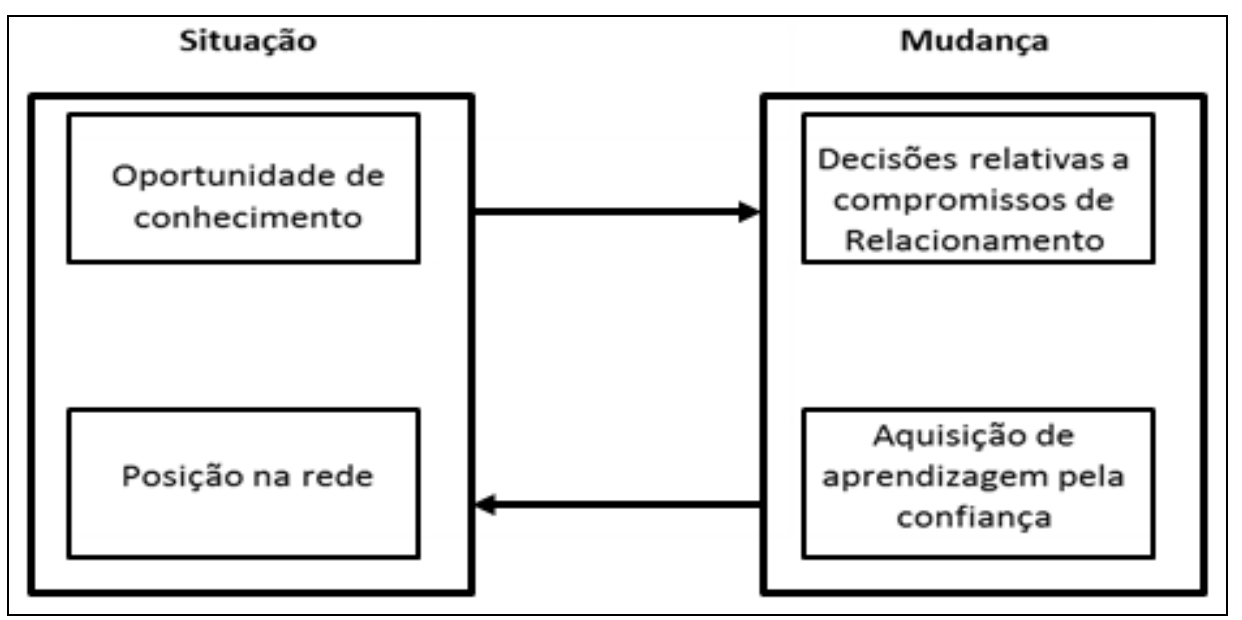

Figura 10 modelo de processo de internacionalização da rede de negócios (a versão de 2009). Fonte: Johanson e Vahlne (2009, p. 1424). 


\section{INTERNACIONALIZAÇÃO DE CURSOS STRICTO SENSU: UMA INVESTIGAÇÃO SOBRE A \\ DISTÂNCIA PSÍQUICA E AS PRÁTICAS ADOTADAS \\ DOI: http://dx.doi.org/10.5007/1983-4535.2016v9n2p260}

A figura 1 apresenta uma revisão do modelo de 1977 de Johanson e Vahlne. Percebese que neste modelo revisado, é dada uma perspectiva mais voltada a relação, onde a oportunidade de conhecimento leva a tomada de decisões relativas a compromissos de relacionamentos e isto gera uma aprendizagem advinda pela relação de confiança, fazendo com que a empresa venha a melhorar a sua posição na rede.

Johanson e Vahlne (2009) dão mais importância à formação de rede, sugerindo uma premissa básica para o fortalecimento das relações internacionais. Ademais, dão enfoque às relações constantes entre os parceiros sobre forma de gerar benefícios múltiplos e comuns.

\subsection{INTERNACIONALIZAÇÃO DE IES}

As IES possuem um trabalho que as distinguem dos outros segmentos, são instituições auto reprodutivas, já que estão sempre formando o conhecimento (MARGINSON, 2007). Brennnan e Garvey (2009) destacam que há um dinâmico ritmo de internacionalização em empresas que trabalham com intenso conhecimento.

De uma perspectiva histórica, a internacionalização do ensino superior ocorre desde o surgimento das universidades medievais na Europa no século XII (HUANG, 2007). O modelo original de universidades era de um ambiente cosmopolita, mais adiante, especialmente pós $1^{\text {a }}$ guerra, elas começaram a ter uma orientação maior para a sua nação, com uma participação mais intensa do governo sobre suas ações. Mais recentemente, as IES estão cada vez mais se voltando novamente para a internacionalização (KERR, 1990; ALTBACH; KNIGHT, 2007).

"A internacionalização é um processo complexo e contínuo, que envolve todos os setores da universidade" (BOSTROM, 2010, p. 158). Murphy (2007) já dizia que a internacionalização de IES é um processo e não um evento; sendo que seu objetivo é o aprendizado em conjunto entre professores e alunos de diferentes nações; sendo a internacionalização benéfica e essencial na maioria das universidades em todo o mundo.

Em IES, a internacionalização emerge ao longo de um longo período de tempo e existem muitas variáveis que contribuem para as fases da internacionalização (BOGOTCH; MASLIN-OSTROWSKI, 2010). A internacionalização de IES requer um profundo conhecimento e o efeito da internacionalização deve contribuir para o aprendizado do aluno (CORYELL et al., 2012; OLATOKUN; UTULU, 2012). Além de alunos, a internacionalização de IES pode gerar um efeito para professores e funcionários (CORYELL et al., 2012; OLATOKUN; UTULU, 2012). 


\section{INTERNACIONALIZAÇÃO DE CURSOS STRICTO SENSU: UMA INVESTIGAÇÃO SOBRE A \\ DISTÂNCIA PSÍQUICA E AS PRÁTICAS ADOTADAS \\ DOI: http://dx.doi.org/10.5007/1983-4535.2016v9n2p260}

Professores buscam participar de programas de internacionalização para incrementarem o seu currículo (BOGOTCH; MASLIN-OSTROWSKI, 2010). Esta experiência internacional acaba fazendo com que as universidades tenham uma competência docente, e isto acaba forçando os professores a mudarem a sua conduta e até mesmo sua cultura (CAVUSGIL, 1998).

Além de professores e funcionários da IES, os alunos também são beneficiados, já que a internacionalização melhora a cultura do aluno (ALTBACH; KNIGHT, 2007). A cultura do aluno é ampliada principalmente em programas de intercâmbio, já que eles beneficiam as relações individuais, especialmente favorecendo o conhecimento de novas culturas (BAERNHOLDT et al., 2013). O intercâmbio de alunos fora do país oferece benefícios tanto para alunos e universidades, como para a sociedade em geral (MURPHY, 2007), sendo que os estudantes que participam de intercâmbio internacional são vistos como distintos pela universidade (CORYELL et al., 2012).

A participação de estudantes, especialmente em nível de pós-graduação, é essencial para o sucesso da internacionalização de IES (BOGOTCH; MASLIN-OSTROWSKI, 2010). A participação destes e dos demais interessados não deve ser imposta e sim estimulada (BOGOTCH; MASLIN-OSTROWSKI, 2010).

A internacionalização das IES pode ocorrer de diversas maneiras. Baseado nesta condição elaborou-se um quadro representativo, conforme demonstrado a seguir.

\begin{tabular}{|l|l|}
\hline \multicolumn{1}{|c|}{ Formas de Internacionalização } & \multicolumn{1}{c|}{ Autor(es) } \\
\hline Intercâmbio de alunos & $\begin{array}{l}\text { Kerr (1990), Paige (2003), Altbach e King (2007), Huang } \\
\text { (2007), Murphy (2007), Bégin-Caouette (2012), Olatokun e } \\
\text { Utulu (2012), Baernholdt (2013). }\end{array}$ \\
\hline Intercâmbio de professores & $\begin{array}{l}\text { Kerr (1990), Paige (2003), Altbach e King (2007), Murphy } \\
\text { (2007), Bégin-Caouette (2012). }\end{array}$ \\
\hline Pesquisa em conjunto & Huang (2007), Coryell et al. (2012). \\
\hline Publicação e revistas estrangeiras & Bogotch e Maslin-Ostrowski, (2010), Byun e Kim (2011). \\
\hline Currículos adaptados & $\begin{array}{l}\text { Kerr (1990), Paige (2003), Huang (2007), Bogotch e Maslin- } \\
\text { Ostrowski, (2010), Coryell et al. (2012). }\end{array}$ \\
\hline Programas adaptados & Bégin-Caouette (2012). \\
\hline Cursos a distância & Altbach e King (2007). \\
\hline Presença física (unidades no exterior) & Paige (2003), Altbach e King (2007). \\
\hline Visita de professores & Paige (2003). \\
\hline Alunos estrangeiros & Bégin-Caouette (2012), Coryell et al. (2012). \\
\hline
\end{tabular}

Quadro 1 Formas de Internacionalização.

Fonte: autores (2014). 


\section{INTERNACIONALIZAÇÃO DE CURSOS STRICTO SENSU: UMA INVESTIGAÇÃO SOBRE A \\ DISTÂNCIA PSÍQUICA E AS PRÁTICAS ADOTADAS \\ DOI: http://dx.doi.org/10.5007/1983-4535.2016v9n2p260}

O quadro 1 demonstra 10 maneiras que uma IES tem de se internacionalizar. Percebese que o intercâmbio de alunos é o modo mais citado de acordo com as pesquisas realizadas, seguido pelo intercâmbio de professores e adaptação de currículos.

Todos estes aspectos mencionados sobre a internacionalização de IES se adequam aos cursos stricto sensu, já que os mesmos são serviços oferecidos pelas IES. No entanto, a aplicabilidade destas ações pode variar de acordo com a distância psíquica, sendo pertinente o estudo do seu impacto para as IES, especialmente para os cursos stricto sensu, foco de análise do presente estudo. Assim sendo, buscou-se analisar o comportamento de cursos stricto sensu em uma IES no sul do país, sendo que a seguir será demonstrado como isto ocorreu.

\section{METODOLOGIA}

A pesquisa caracteriza-se por se exploratória e qualitativa. As informações foram obtidas por meio de entrevistas, guiadas por um roteiro semiestruturado. As questões abordadas foram extraídas com base na revisão da literatura, buscando responder aos objetivos deste trabalho.

O roteiro de entrevista foi dividido em duas partes, a primeira composta por informações específicas do curso em estudo e a segunda contendo questões da entrevista, que compreendeu os seguintes assuntos: escolha do país e distância psíquica, determinantes e incertezas, formas de internacionalização, conhecimento e aprendizado, vantagens e efeitos da internacionalização, rede de relações e barreiras existentes.

Foram entrevistados cinco coordenadores de sete cursos stricto sensu da FURB, dois cursos de doutorado e cinco de mestrado. Cabe ressaltar que dois coordenadores responderam por dois cursos, assim sendo, perfazendo um total de sete cursos. Também foi entrevistado o coordenador do Núcleo de Relações Internacionais da FURB, no sentido de averiguar de que forma a IES vem trabalhando com a internacionalização.

As entrevistas foram gravadas e realizadas anotações face-a-face. Após, analisou-se as anotações e as gravações para interpretação das informações. A primeira entrevista foi realizada no dia 25/06/2014 com a coordenação do curso de mestrado em Saúde Coletiva e durou 34 minutos e 27 segundos. A segunda entrevista ocorreu com a coordenação do curso de doutorado em Ciências Contábeis e Administração e mestrado em Ciências Contábeis no dia 26/06/2013 e teve duração de 21 minutos e 59 segundos. A terceira ocorreu no mesmo dia com a coordenação do curso de mestrado em Administração e durou 20 minutos e 15 
segundos. A quarta aconteceu no dia 10/07/2014 com a vice-coordenadora do Doutorado e Mestrado em Desenvolvimento Regional, com duração de 29 minutos e 14 segundos.

A entrevista com o coordenador do Núcleo de Relações Internacionais ocorre no dia 11/07/2014 e teve duração de 25 minutos e 30 segundos. Já a entrevista com a coordenação do mestrado em Educação aconteceu dia 15/07/2014 e teve duração de 34 minutos e 37 segundos. Ao todo, foram 2 horas, 46 minutos e 2 segundos de entrevistas.

\section{RESULTADOS DA PESQUISA}

A apresentação dos resultados será dividida em seções, cada uma explorando os resultados das entrevistas categorizados de acordo com tópicos investigativos. A primeira investigação abordará as formas de internacionalização.

\subsection{FORMAS DE INTERNACIONALIZAÇÃO}

Por meio das entrevistas, verificou-se que os cursos de doutorado implementam a internacionalização quando professores participam de programas no exterior, quando alunos fazem o doutorado sanduiche, quando recebem professores de fora para palestras ou participar de bancas, e ainda, no momento em que ocorrem pesquisas em conjunto.

Todos os coordenadores destacaram a importância dos convênios com outras IES de fora como uma importante estratégia de firmar a internacionalização. Percebeu-se que o doutorado é o curso que mais possui parcerias e o que menos possui é o mestrado em saúde coletiva, o mais novo dos cursos. Isto remete a ideia de que o processo de internacionalização é gradual, conforme destacado por Forsgren (2002).

O quadro 2 menciona as formas de internacionalização dos cursos pesquisados.

\begin{tabular}{|l|c|c|c|c|c|c|c|}
\hline \multicolumn{1}{|c|}{ Ação adotada } & DCCA & DDR & MA & MCC & MSC & MDR & ME \\
\hline Intercâmbio de Professores & $\mathrm{X}$ & $\mathrm{X}$ & $\mathrm{X}$ & $\mathrm{X}$ & $\mathrm{X}$ & $\mathrm{X}$ & $\mathrm{X}$ \\
\hline Intercâmbio de Alunos & $\mathrm{X}$ & $\mathrm{X}$ & & & & & $\mathrm{X}$ \\
\hline Publicações & $\mathrm{X}$ & $\mathrm{X}$ & $\mathrm{X}$ & $\mathrm{X}$ & $\mathrm{X}$ & $\mathrm{X}$ & $\mathrm{X}$ \\
\hline Palestras & $\mathrm{X}$ & $\mathrm{X}$ & & & & & $\mathrm{X}$ \\
\hline Participação em bancas & $\mathrm{X}$ & & & & & & $\mathrm{X}$ \\
\hline
\end{tabular}

Quadro 2 Formas de Internacionalização.

Legenda: DCCA - Doutorado em Ciências Contábeis e Administração, DDR - Doutorado em Desenvolvimento Regional, MA - Mestrado em Administração, MCC - Mestrado em Ciências Contábeis, MSC - Mestrado em Saúde Coletiva, MDR - Mestrado em Desenvolvimento Regional e ME - Mestrado em Educação.

Fonte: dados da pesquisa. 


\section{INTERNACIONALIZAÇÃO DE CURSOS STRICTO SENSU: UMA INVESTIGAÇÃO SOBRE A \\ DISTÂNCIA PSÍQUICA E AS PRÁTICAS ADOTADAS \\ DOI: http://dx.doi.org/10.5007/1983-4535.2016v9n2p260}

Percebe-se pelo quadro 2 que a publicação e o intercâmbio de professores são as ações internacionais mais adotadas pelos cursos. Chama a atenção que os cursos de doutorado e o mestrado mais antigo são os cursos que possuam mais ações de internacionalização.

O mestrado Educação, o mais antigo, apresentou mais opções de internacionalização, juntamente com o doutorado em Administração e Ciências Contábeis. O curso possui projetos em andamento com 10 universidades estrangeiras. O foco destas relações é a qualificação do curso e busca-se com constância a publicação internacional em conjunto.

A mobilidade de professores juntamente com a publicação são as duas principais formas de internacionalização. A mobilidade de professores como uma forma de internacionalização já havia sido ressaltada por Altbach e Knight (2007), Marginson (2007), Byun e Kim (2011) e Bégin-Caouette (2012). Todos concordam que a mobilização de professores é intensificada quando há parcerias com instituições estrangeiras e que contribui para a melhora na qualidade do ensino, conforme descrito por Bégin-Caouette (2012).

Buckley (2002) enfatiza que as organizações começam a se internacionalizar inicialmente de uma maneira não planejada, no entanto, com o tempo, é importante criar uma definição estratégica no processo de internacionalização. Esta falta de estratégias faz com que os professores trabalhem praticamente sozinhos, sendo que muitas atividades de internacionalização implantadas por eles se querem é de conhecimento dos colegas, conforme destacada pela coordenadora do curso de Administração. Verificou-se no curso de Saúde Coletiva que até existe uma integração de professores, mas isto ocorre mediante projetos formais. No doutorado em Administração e Ciências Contábeis e mestrado em Ciências Contábeis, também a figura do professor é decisiva para a execução das estratégias de internacionalização, mas como destacado, ocorre esporadicamente sem envolver o conjunto. No doutorado e mestrado em Desenvolvimento Regional não é diferente, percebeu-se na entrevista que os professores trabalham isoladamente.

O fato mais marcante ocorreu no Núcleo de Relações Internacionais, onde a saída de professores já acarretou em uma perda de convênio, isto porque não havia outro profissional para intensificar aquele que foi firmado. Neste caso, o acordo na prática, acontecia somente pela participação de um professor, onde não havia mais profissionais para apoiar a execução do convênio internacional. Estas evidências contribuem para o surgimento da proposição: 
P1: a falta de congruência entre os envolvidos prejudica as ações de internacionalização.

Não se observou a internacionalização de currículo como uma prática de internacionalização, conforme sugerido Kerr (1990), Paige (2003), Huang (2007), Bogotch e Maslin-Ostrowski (2010), Bégin-Caouette (2012), Coryell et al. (2012), Olatokun e Utulu (2012), Baernholdt (2013), Fathi Vajargah e Khoshnoodifar (2013) e Berry (2014).

Outra estratégia destaca, especialmente pelo coordenador do doutorado em Ciências Contábeis e Administração e do mestrado em Ciências Contábeis foi o uso da tecnologia. Segundo ele, ela possibilita que se faça algum processo de internacionalização, como conferências on-line e publicações em conjunto, sem haver a necessidade de deslocamento e presença física. Mcdougall e Oviatt (1994) já diziam que a tecnologia é um aspecto facilitador para a internacionalização. O Núcleo de Negócios Internacionais utiliza o facebook para se comunicar com seus parceiros, um exemplo disto, é que uma postagem acarretou mais de mil curtidas em mais de vinte países.

Nesta mesma perspectiva, Thune e Welle-Strand (2005) reforçam que a tecnologia contribui significativamente para impulsionar a internacionalização de uma IES, o que se confirma nesta pesquisa.

\subsection{ESCOLHA DO PAÍS E DISTÂNCIA PSÍQUICA}

Pelo modelo de Uppsala, empresas começam a se internacionalizarem em mercados vizinhos e posteriormente, em mercados com menor distância psíquica, inicialmente com um baixo compromisso (JOHANSON; VAHLNE, 2009), sendo que ao iniciar o seu processo de internacionalização, as organizações devem escolher países psicologicamente mais pertos, levando em conta a distância psíquica (ANDERSSON, 2004). Quanto maior a distância psíquica, maior o desconhecimento (JOHANSON; VAHLNE, 2009).

Entretanto, não se percebeu a distância psíquica como um fator determinante para os cursos pesquisados. No curso de mestrado em Saúde Coletiva, existem dois convênios, um com uma IES de Portugal e outro com uma IES da Alemanha. A escolha por Portugal não ocorreu em função de ser um país de língua portuguesa, e sim pelo fato da orientadora de doutorado da coordenadora do curso ser de lá. A IES alemã sim, foi pela distância psíquica, 
mas quem deu início ao processo foi a IES alemã escolhendo a FURB pelo fato de estar localizada em uma região com descendência alemã.

No mestrado em Administração existem convênios com a França, Espanha, Suécia, Portugal e Alemanha. Apesar de Portugal e Alemanha poderem ter sido escolhidos pela distância psíquica, não foi este o motivo. O motivo de escolha de todos os parceiros do curso de Administração foi por iniciativa dos docentes, pela rede de contatos, o mesmo caso do curso de Saúde Coletiva em relação à Portugal. O mestrado em Educação tem parceria com instituições da Espanha, Portugal, França, Canadá, Alemanha, Argentina e Suécia.

O doutorado em Ciências Contábeis e Administração e o mestrado em Ciências Contábeis possuem o mesmo convênio, com IES da Espanha, França, Suécia e Canadá. A escolha das opções também ocorreu pela rede de contato dos professores e coordenado do curso, o qual realizou seu doutorado na Espanha. $O$ doutorado e mestrado em Desenvolvimento Regional possui parcerias com instituições da Argentina, Espanha, Canadá, Chile e Portugal.

Todos os representantes de cursos foram unanimes em afirmar que a rede de relações é formada pelo contato dos professores. Após estas indagações, foi mencionado se a distância psíquica era um fator de influência, e isto não foi confirmado por nenhum deles. Os resultados vão ao encontro de Raboch e Domingues (2008), os quais já haviam verificado que a FURB possui uma tendência de internacionalização por meio de parcerias e relações em rede, especialmente pelo network de professores, sendo isto também confirmado nos cursos stricto sensu.

Como percebido, outro fator parece ser mais significativo que a distância psíquica para a escolha do país, o que sugere a criação da segunda proposição:

\section{P2: A escolha do país ocorre pela rede de contato dos professores.}

A coordenadora do curso de Administração destacou que existe uma tendência de escolha de IES parceiras que se sobressai a distância psíquica que é a credibilidade do parceiro. Para ela, o curso se fortalece quando firma um acordo de parceria com uma IES mais renomada, o qual busca aprender. A importância de IES renomada também foi destacada pelo coordenador do doutorado em Ciências Contábeis e Administração e o mestrado em Ciências Contábeis. Neste caso, elabora-se a terceira proposição: 
P3: A credibilidade influencia na escolha de outras IES como parceiros no exterior.

O curso de mestrado em Educação reforça esta crença, já que a troca de experiências entre parceiros mais reconhecidos propicia melhores resultados. A exemplo disto, o curso tem buscado fazer grupos de pesquisa com professores estrangeiros de renomadas universidades, o resultado disto é artigos melhores e publicados em revistas mais conceituadas, o que qualifica mais o corpo docente e por conseguinte o curso.

\subsection{DETERMINANTES E INCERTEZAS}

Percebeu-se nas entrevistas realizadas com todos os cursos, que os principais determinantes para a internacionalização são: reconhecimento (social e internacional), credibilidade, busca pela excelência, visibilidade do curso e ampliação do conhecimento. Tanto a visibilidade do curso quanto a ampliação do conhecimento foram enfatizados como importante por dois dos três coordenadores. O fato de instituições internacionalizarem-se para adquiri conhecimento foi um dos motivos referenciados por Johanson e Vahlne (1977, 2009), o qual aqui se confirma, corroborando com Kerr (1990).

Para o coordenador do doutorado, ao atingir a excelência, o curso acaba tendo um diferencial competitivo, que se reforça quando a CAPES legitima seus esforços de internacionalização e o certifica como um curso de destaque. Estas indagações vão ao encontro de Buckley (2002), ao enfatizar que as instituições que se internacionalizam buscam a competitividade. Hong e Roh (2009) complementam que se almeja a internacionalização como forma de torna-se mais competitivo, e isto foi percebido para cursos stricto sensu.

Em relação às incertezas, todos os coordenadores destacaram haver grandes incertezas sobre os processos de internacionalização e sobre o mercado exterior, no entanto, observou-se que eles encaram isto com naturalidade, nenhum coordenador referenciou a incerteza como um obstáculo, inclusive o coordenador do Núcleo de Relações Internacionais. Para o coordenado do doutorado em Ciências Contábeis e Administração e do mestrado em Ciência Contábeis a "incerteza faz parte do processo". A coordenadora do mestrado em Saúde Coletiva destacou que as incertezas "fazem parte da complexidade existente". O coordenador do Núcleo de Ralações Internacionais disse que as incertezas são inerentes a não execução 


\section{INTERNACIONALIZAÇÃO DE CURSOS STRICTO SENSU: UMA INVESTIGAÇÃO SOBRE A \\ DISTÂNCIA PSÍQUICA E AS PRÁTICAS ADOTADAS \\ DOI: http://dx.doi.org/10.5007/1983-4535.2016v9n2p260}

dos processos, como já ocorrido, de atrasos no visto de entrada de alunos que saem para o exterior, acordos multilaterais com parceiros, na expectativa de que o convênio busque atender a todos os objetivos. No entanto, o coordenador, assim como os demais, em momento algum explanou a incerteza como barreira.

$\mathrm{Na}$ medida em que as incertezas vão diminuindo, outras vão surgindo, isto foi confirmado por todos os coordenadores, indo ao encontro do que foi destacado por Figueirade-Lemos, Johanson e Vahlne (2011).

A premissa básica do modelo de Uppsala destacada por Johanson e Vahlne (1977) se confirmou, a coordenadora do curso de Saúde Coletiva foi à única que enfatizou a inexperiência como fator de incerteza e confirmou a falta de conhecimento como um obstáculo, sendo que com o tempo vai se adquirindo conhecimento. No modelo de Uppsala, o conhecimento e a incerteza são dois conceitos interligados (FIGUEIRA-DE-LEMOS; JOHANSON; VAHLNE, 2011), e isto foi confirmado para os cursos stricto sensu.

No caso de IES, as incertezas diminuem de duas formas, na fase inicial do relacionamento, na medida em que os convênios são firmados. O coordenador do Núcleo de Ralações Internacionais demonstrou convênios realizados com outras IES. Pode-se perceber a existência de acordos bilaterais onde as instituições conveniadas expõem o que irão fazer; isto tende a facilitar a execução das operações e minimizar as incertezas iniciais. Outro fator que minimiza as incertezas é uma maior presença internacional. Neste caso, percebeu-se que a incerteza tende a diminuir pelo comportamento incremental, conforme exposto por Forgren (2002). É normal que a organização reduza a incerteza pelo conhecimento e gere outras incertezas pelas descobertas (FIGUEIRA-DE-LEMOS; JOHANSON; VAHLNE, 2011), e este aspecto também foi evidenciado, já que um maior relacionamento ocasiona um maior contato, minimizando as incertezas existentes e fazendo com que surjam outras.

\subsection{CONHECIMENTO E APRENDIZADO}

Os coordenadores de curso manifestaram que não possuem conhecimento substancial sobre o mercado exterior no início do processo de internacionalização, apenas conhecimento parcial. O conhecimento vai sendo adquirido com o tempo, o que vai ao encontro do modelo de Uppsala de Johanson e Vahlne (1977). Também se confirma uma das proposições de Forsgren (2002), de que organizações, por vezes, investem em mercados estrangeiros sem possuírem conhecimento experimental, e os cursos aceitam o desafio quando a percepção do 


\section{INTERNACIONALIZAÇÃO DE CURSOS STRICTO SENSU: UMA INVESTIGAÇÃO SOBRE A \\ DISTÂNCIA PSÍQUICA E AS PRÁTICAS ADOTADAS \\ DOI: http://dx.doi.org/10.5007/1983-4535.2016v9n2p260}

risco de investir no exterior for menor do que o risco percebido de não investir no exterior, justamente o que foi definido por outra proposição de Forsgren (2002).

Neste caso, o desconhecimento do mercado acaba não sendo uma barreira, já que aos poucos se adquire conhecimento sobre o mercado. O conhecimento do mercado quando existe é do professor que organizou a parceria, ou seja, é um conhecimento individualizado sobre o mercado exterior, conforme destacado pela coordenadora do mestrado em Saúde Pública em suas palavras: "é o professor que possui, ele possui conhecimento da parceria". Estas palavras acabem reforçando a elaboração da terceira proposição.

Na prática, não há uma análise prévia pelo curso antes de se firmar o convênio. Quem possui o conhecimento sobre o mercado, e de maneira superficial, é o professor, sendo ele o principal agente, tanto no início quanto na sequência do convênio. $\mathrm{O}$ conhecimento sobre o mercado aos poucos vai gerando aprendizagem, sendo que a informação adquirida em um primeiro estágio pode servir de base para demais, assim como proposto por Forsgren (2002).

A aprendizagem através do desenvolvimento de conhecimento experimental sobre os mercados estrangeiros é necessária, a fim de superar a "distância psíquica" desses mercados; ou seja, superar as diferenças entre países em termos de língua, cultura, nível educacional, práticas comerciais e legislação (MELIN, 1992).

Buscando um melhor conhecimento sobre o mercado, foi idealizado o modelo de Uppsala. Johanson e Vahlne (1977) descrevem que a premissa básica do modelo de Uppsala é a falta de conhecimento sobre o mercado estrangeiro, e isto acaba sendo um obstáculo para as operações internacionais; no entanto, com o tempo, as organizações vão adquirindo conhecimento, o que fortalece a sua necessidade de internacionalização e a aquisição da aprendizagem leva tempo (JOHANSON; VAHLNE, 2009).

Verificou-se ainda, que os ideais de Brennnan e Garvey (2009) se confirmaram, visto que os cursos buscam a ampliação do conhecimento como uma forma de inovação. Também foi percebida que uma das vantagens da internacionalização é a troca de informações, onde as experiências adquiridas em outro país é uma forma de transferir o conhecimento (HSU; PEREIRA, 2008).

Johanson e Vahlne (2009) destacam que novos conhecimentos são desenvolvidos pelo relacionamento, e isto foi confirmado ao analisar as entrevistas. Para os cursos, percebeu-se que o desenvolvimento no relacionamento contribui para o conhecimento de novas teorias abordadas e as tendências de pesquisa. As novas teorias advêm de artigos, pesquisas e 
contatos com outros professores. As tendências de pesquisa são percebidas em artigos e eventos científicos.

\subsection{REDE DE RELAÇÕES}

A rede de relações foi destacada por todos como preponderante para o processo de internacionalização. Johanson e Vahlne (2009) alertaram sobre a importância de criar uma rede de parceiros e isto levado a sério pelos cursos investigados. Na prática, as relações são protocoladas e de fato, a rede de contatos acaba influenciando na escolha do local de internacionalização, justamente como referenciado por Andersson (2004) e Johanson e Vahlne (2009).

Johanson e Vahlne (2009) ainda destacaram que a rede de relações reduz a incerteza e gera conhecimento, e isto fato ocorre com os cursos stricto sensu. Além da geração de conhecimento, que já foi evidenciada, a redução da incerteza ocorre com a troca de informações entre os envolvidos. Os autores alertam que novos conhecimentos são desenvolvidos pelo relacionamento, sendo que as redes de relações são decisivas para o sucesso da empresa, já que elas ocasionam aprendizado, confiança e compromisso (JOHANSON; VAHLNE, 2009).

Johanson e Vahlne (2009) destacavam que confiança e o compromisso são baseados em acordos formais. Para os cursos pesquisados, os acordos formais de fato são uma maneira de propiciar mais incerteza e compromisso entre os conveniados. Na sequência elucidaram-se as formas de internacionalização.

\begin{tabular}{|l|l|}
\hline \multicolumn{1}{|c|}{ Oportunidade de conhecimento } & \multicolumn{1}{c|}{$\begin{array}{c}\text { Decisões relativas a compromissos de } \\
\text { relacionamento }\end{array}$} \\
\hline $\begin{array}{l}\text { - Por meio do corpo docente; } \\
\text { - Participação de eventos internacionais; } \\
\text { - Intercâmbio de professores; } \\
\text { - Intercâmbio de alunos. }\end{array}$ & \begin{tabular}{l}
\multicolumn{1}{c|}{ - Aceitar professores de outras IES; } \\
- Aceitar alunos de outras IES; \\
- Participar de eventos internacionais; \\
\multicolumn{1}{|c|}{ Posição na rede }
\end{tabular} \\
\hline $\begin{array}{l}\text { - Participar de trabalhos em conjunto (artigos, } \\
\text { pesquisas...). }\end{array}$ \\
\hline $\begin{array}{l}\text { - Aumento de network; } \\
\text { - Participação mais ativa; } \\
\text { - Novos professores; } \\
\text { - Professores mais bem preparados; } \\
\text { - Alunos com experiência internacional; } \\
\text { - Melhores artigos. }\end{array}$ & \multicolumn{1}{|c|}{ Aquisiço de aprendizagem pela confiança } \\
\hline
\end{tabular}

Quadro 3 Formas de Internacionalização.

Fonte: dados da pesquisa. 


\section{INTERNACIONALIZAÇÃO DE CURSOS STRICTO SENSU: UMA INVESTIGAÇÃO SOBRE A \\ DISTÂNCIA PSÍQUICA E AS PRÁTICAS ADOTADAS \\ DOI: http://dx.doi.org/10.5007/1983-4535.2016v9n2p260}

O quadro 3 apresenta a interação entre a oportunidade de conhecimento, as decisões relativas a compromissos de relacionamento, a aquisição da aprendizagem pela confiança e a posição na rede, conforme modelo original de Johanson e Vahlne (2009). Com o tempo, vai aumentando o compromisso e a confiança nas instituições conveniadas, o que propicia uma melhor posição para o curso, indo ao encontro com os achados de Johanson e Vahlne (2009).

Percebe-se que os cursos stricto sensu aproveitam uma oportunidade de conhecimento sobre o mercado internacional por meio dos professores do quadro, participação em eventos internacionais, intercâmbio de professores e de alunos.

O modelo original, que serviu de base, não especifica o que pode ocorrer com o aumento do compromisso e não explica como as redes foram criadas (JOHANSON; VAHLNE, 2009). Aqui, para os cursos strcito sensu, consegue-se chegar a estas respostas. Inicialmente observou-se que a decorrência do aumento do compromisso faz com que os cursos melhorem a sua posição na rede de relacionamento, os quais amentam a sua network, fazem com que os cursos tenham uma participação mais ativa, contam com novos professores, oriundos de outros países, seus professores se qualificam, os alunos adquirem experiência internacional e melhora a qualidade dos artigos publicados pelos cursos.

Estes itens elencados acabam fortificando os cursos strcito sensu, e os tornando mais competitivos, conforme destacado por Buckley (2002), Hitt (2006) e Hong e Roh (2009). Buckley (2002) enfatiza que as empresas começam a se internacionalizar inicialmente de uma maneira não planejada, sendo que nas entrevistas, todos os coordenadores de curso manifestaram que não fazem um planejamento formal para a internacionalização, ou seja, ela apesar de não planejada, contribui para o crescimento do curso.

Hitt (2006) manifestou que a rede de relações interfere positivamente no processo de internacionalização, impactando no desempenho da organização, incluindo neste caso, os cursos stricto sensu, conforme averiguado nas entrevistas realizadas.

Forsgren (2002) destaca que as organizações buscam conhecimento incremental, sendo que isto se aplica aos cursos, mais especificamente pelos benefícios das redes, já mencionado por Johanson e Vahlne (2009). Neste caso, os cursos stricto sensu adquirem conhecimento incremental e as redes de relações ajudam a gerar conhecimento.

Percebeu-se que a rede pode ser uma forma de reduzir a distância psíquica, corroborando com Johanson e Vahlne (2009). Isto ocorre porque os cursos buscam constantemente contato com as IES parceiras para obter informações sobre aspectos 
desconhecidos, o que ajuda a miniminizar as incertezas e os coloca mais próximos ao mercado internacional.

Em relação à formação na rede, outra indagação sugerida por Johanson e Vahlne (2009), verificou-se que os cursos sricto sensu foram às redes pelos contatos pessoais dos seus docentes, conforme destacado na elaboração da primeira proposição.

\section{CONCLUSÃO}

O objetivo do presente artigo foi verificar se a distância psíquica é levada em consideração no processo de internacionalização de cursos stricto sensu de IES brasileiras. Pelos estudos realizados, constatou-se que a rede de contatos dos professores se sobressai à distância psíquica, sendo que para os cursos pesquisados, a distância psíquica não interfere na escolha de parceiros. Portanto, confirmando os achados de Johanson e Vahlne (2009), a rede de contatos reduz a distância psíquica. Neste caso, a rede contribui para o fortalecimento dos cursos stricto sensu da FURB, ação está já descrita por Raboch e Domingues (2008). Assim sendo, foi criada a seguinte proposição: a escolha do país ocorre pela rede de contato dos professores.

Verificou-se ainda, a existência do conhecimento incremental, conforme destacado por Johanson e Vahlne (1977) e Forsgren (2002), e isto se confirmou nos cursos pesquisados. Na prática, eles iniciam o processo de internacionalização sem ter conhecimento substancial sobre o mercado, e aos poucos, vão adquirindo conhecimento.

Outra questão instigante foi o que levaria os cursos stricto sensu a se internacionalizarem-se? Percebeu-se que os principais determinantes para a internacionalização são: reconhecimento (social e internacional), credibilidade, busca pela excelência, visibilidade do curso e ampliação do conhecimento, sendo este último um dos principais motivos, até porque, trata-se de um ambiente que trabalha com geração de conhecimento.

Para poder gerar conhecimento, os cursos stricto sensu procuram parceiros renomados. Estes achados sugerem a seguinte proposição: a credibilidade influencia na escolha de outras IES como parceiros no exterior. Uma forma eficiente de garantir os parceiros é por meio de acordos formais, no geral, os cursos buscam criar rede de relações. A rede de relações foi destacada por todos como preponderante para o processo de internacionalização. Na prática, as relações são protocoladas e de fato, a rede de contatos acaba influenciando na escolha do 


\section{INTERNACIONALIZAÇÃO DE CURSOS STRICTO SENSU: UMA INVESTIGAÇÃO SOBRE A \\ DISTÂNCIA PSÍQUICA E AS PRÁTICAS ADOTADAS \\ DOI: http://dx.doi.org/10.5007/1983-4535.2016v9n2p260}

local de internacionalização, justamente como referenciado por Andersson (2004) e Johanson e Vahlne (2009).

Hitt (2006) confirmou que a rede de relações interfere positivamente no processo de internacionalização, impactando no desempenho da organização, incluindo neste caso, os cursos stricto sensu. A rede de contatos é uma forma de minimizar as incertezas e maximizar a confiança entre os envolvidos. Com o tempo, vai aumentando o compromisso e a confiança nas instituições conveniadas, indo ao encontro com os achados de Johanson e Vahlne (2009), ao esclarecerem que um maior compromisso tende a ocorrer com o tempo.

Além da falta de planejamento, percebeu-se a falta de congruência entre os professores, portanto, definiu-se a próxima proposição: a falta de congruência entre os envolvidos prejudica as ações de internacionalização. Neste caso, sugere-se que a existência de estratégias planejadas e a congruência tende a propiciar melhores resultados de internacionalização.

O aprendizado dos cursos ocorre de maneira incremental, conforme destacado por Forsgren (2002). O conhecimento vai sendo adquirido com o tempo, justamente como preconizado no modelo de Uppsala de Johanson e Vahlne (1977). Este aprendizado pode ocasionar a inovação, indo ao encontro das sugestões de Brennnan e Garvey (2009).

Todos os entrevistados afirmaram que a infraestrutura interfere no processo de internacionalização, o que confirma as crenças de Bogotch e Maslin-Ostrowski (2010). A infraestrutura institucional limitada e a falta de recursos financeiros para esta finalidade foram destacadas por Bogotch e Maslin-Ostrowski (2010), sendo que o fator financeiro é um grande impeditivo para que alunos venham a querer estudar no exterior (MURPHY, 2007).

Forsgren (2002) destaca que as organizações buscam conhecimento incremental, sendo que isto se aplica aos cursos, mais especificamente pelos benefícios das redes, já mencionado por Johanson e Vahlne (2009). Neste caso, os cursos stricto sensu adquirem conhecimento incremental e as redes de relações ajudam a gerar conhecimento. Na prática, os cursos melhoram a sua posição na rede e por conseguinte, amentam a sua network, fazem com que os cursos tenham uma participação mais ativa, contam com novos professores, oriundos de outros países, seus professores se qualificam, os alunos adquirem experiência internacional e melhora a qualidade dos artigos publicados pelos cursos.

Em termos de contribuições gerencias, cursos stricto sensu precisam contar com professores e alunos que tenham pelo menos, o conhecimento da língua inglesa, além de 
objetivarem o planejamento dos processos de internacionalização e uma aplicação de forma que venha a aglutinar todos os professores. Ademais, é preciso haver um apoio da IES, com intuito de amparar os cursos stricto sensu nas suas estratégias de internacionalização. Também recomenda-se o uso da tecnologia como efeito minimizador de custos e maximizador das atividades internacionais. Por fim, sugere-se que IES possuam professores que tenham contatos com colegas de outras IES internacionais, já que isto é uma prerrogativa decisiva para a internacionalização de IES.

No que concerne à contribuição científica, observou-se que a distância psíquica não é decisiva para a escolha de novos mercados e a e a falta de conhecimento sobre o mercado exterior não e um obstáculo. Por fim, percebeu-se que a geração de conhecimento faz parte das universidades, e que, além de ser uma questão de sobrevivência, pode ser um diferencial competitivo, sendo que ela tende a ocorrer paulatinamente.

\section{REFERÊNCIAS}

ALTBACH, Philip G.; KNIGHT, Jane. The internationalization of higher education: Motivations and realities. Journal of studies in international education, v. 11, n. 3-4, p. 290-305, 2007.

ANDERSSON, Svante. Internationalization in different industrial contexts. Journal of Business Venturing, v. 19, n. 6, p. 851-875, 2004.

BAERNHOLDT, M. et al. Fostering internationalization: an American-Danish semester-long undergraduate nursing student exchange program. International nursing review, v. 60 , n. 2 , p. 221-227, 2013.

BÉGIN-CAOUETTE, Olivier. The internationalization of in-service teacher training in Québec cégeps and their foreign partners: An institutional perspective. Prospects, v. 42, n. 1, p. $91-112,2012$.

BERRY, Theodorea Regina. Internationalization, Internalization, and Intersectionality of Identity: A Critical Race Feminist Re-Images Curriculum. Journal of Curriculum Theorizing, v. 30, n. 1, 2014.

BOGOTCH, Ira; MASLIN-OSTROWSKI, Patricia. Internationalizing educational leadership: How a university department jumps the curve from local to international. Educational Administration Quarterly, v. 46, n. 2, p. 210-240, 2010.

BRENNAN, L.; GARVEY, D. The role of knowledge in internationalization. Research in International Business and Finance, v. 23, n. 2, p. 120-133, 2009. 
BOSTROM, Cheryl A. Diffusion of internationalization in Turkish higher education. Journal of studies in international education, v. 14, n. 2, p. 143-160, 2010.

BUCKLEY, Peter J. Is the international business research agenda running out of steam?. Journal of international business studies, v. 33, n. 2, p. 365-373, 2002.

BYUN, Kiyong; KIM, Minjung. Shifting patterns of the government's policies for the internationalization of Korean higher education. Journal of Studies in International Education, v. 15, n. 5, p. 467-486, 2011.

CAVUSGIL, S. Tamer. Internationalizing doctoral education in business: A call for action. Thunderbird International Business Review, v. 40, n. 1, p. 77-85, 1998.

CORYELL, Joellen Elizabeth et al. Case Studies of Internationalization in Adult and Higher Education Inside the Processes of Four Universities in the United States and the United Kingdom. Journal of Studies in International Education, v. 16, n. 1, p. 75-98, 2012.

FATHI VAJARGAH, Kourosh; KHOSHNOODIFAR, Mehrnoosh. Toward a Distance Education Based Strategy for Internationalization of the Curriculum in Higher Education of Iran. Turkish Online Journal of Educational Technology, v. 12, n. 2, 2013.

FIGUEIRA-DE-LEMOS, Francisco; JOHANSON, Jan; VAHLNE, Jan-Erik. Risk management in the internationalization process of the firm: A note on the Uppsala model. Journal of World Business, v. 46, n. 2, p. 143-153, 2011.

FORSGREN, Mats. The concept of learning in the Uppsala internationalization process model: a critical review. International business review, v. 11, n. 3, p. 257-277, 2002.

HITT, Michael A. et al. The importance of resources in the internationalization of professional service firms: The good, the bad, and the ugly. Academy of Management Journal, v. 49, n. 6, p. 1137-1157, 2006.

HONG, Paul; ROH, James. Internationalization, product development and performance outcomes: A comparative study of 10 countries. Research in International Business and Finance, v. 23, n. 2, p. 169-180, 2009.

HSU, Chin-Chun; PEREIRA, Arun. Internationalization and performance: The moderating effects of organizational learning. Omega, v. 36, n. 2, p. 188-205, 2008.

HUANG, Futao. Internationalisation of Higher Education in the Era of Globalisation: What have been its Implications in China and Japan?. Higher Education Management and Policy, v. 19, n. 1, p. 47, 2007.

JACKSON, Jane. Globalization, internationalization, and short-term stays abroad. International Journal of Intercultural Relations, v. 32, n. 4, p. 349-358, 2008. 
JOHANSON, Jan; VAHLNE, Jan-Erik. The internationalization process of the firm - a model of knowledge development and increasing foreign market commitments. Journal of international business studies, v. 8, n. 1, p. 23-32, 1977.

JOHANSON, Jan; VAHLNE, Jan-Erik. The Uppsala internationalization process model revisited: from liability of foreignness to liability of outsidership. Journal of international business studies, v. 40, n. 9, p. 1411-1431, 2009.

KERR, Clark. The internationalisation of learning and the nationalisation of the purposes of higher education: Two'laws of motion'in conflict?. European Journal of Education, p. 5-22, 1990.

MARGINSON, Simon. Globalisation, the" idea of a university" and its ethical regimes. Higher Education Management and Policy, v. 19, n. 1, p. 31, 2007.

MCDOUGALL, Patricia Phillips; OVIATT, B. M. Toward a theory of international new ventures. Journal of international business studies, v. 25, n. 1, p. 45-64, 1994.

MELIN, Leif. Internationalization as a strategy process. Strategic Management Journal, v. 13, n. S2, p. 99-118, 1992.

MURPHY, Moira. Experiences in the internationalization of education: Strategies to promote equality of opportunity at Monterrey Tech. Higher Education, v. 53, n. 2, p. 167-208, 2007.

OLATOKUN, Wole Michael; UTULU, Samuel C. Avemaria. Internationalization of information science education in Nigeria A review of attempts by the Africa Regional Centre for Information Science. IFLA journal, v. 38, n. 2, p. 166-174, 2012.

PAIGE, R. Michael. The American case: The University of Minnesota. Journal of Studies in International Education, v. 7, n. 1, p. 52-63, 2003.

SAPIENZA; Harry J.; AUTIO, Erkko; ZAHRA, Shaker. Effects of Internationalization on Young Firms' Prospects for Survival and Growth. Academy of Management Best Conference, Paper 2003 ENT: G 1.

RABOCH, Henrique; DOMINGUES, Maria José Carvalho de Souza. A Internacionalização do Ensino Superior: o caso da Universidade Regional de Blumenau. VI Simpósio de Gestão e Estratégia em Negócios. Seropédica, RJ, Brasil, Setembro de 2008.

THUNE, Taran; WELLE-STRAND, Anne. ICT for and in internationalization processes: A business school case study. Higher Education, v. 50, n. 4, p. 593-611, 2005. 